
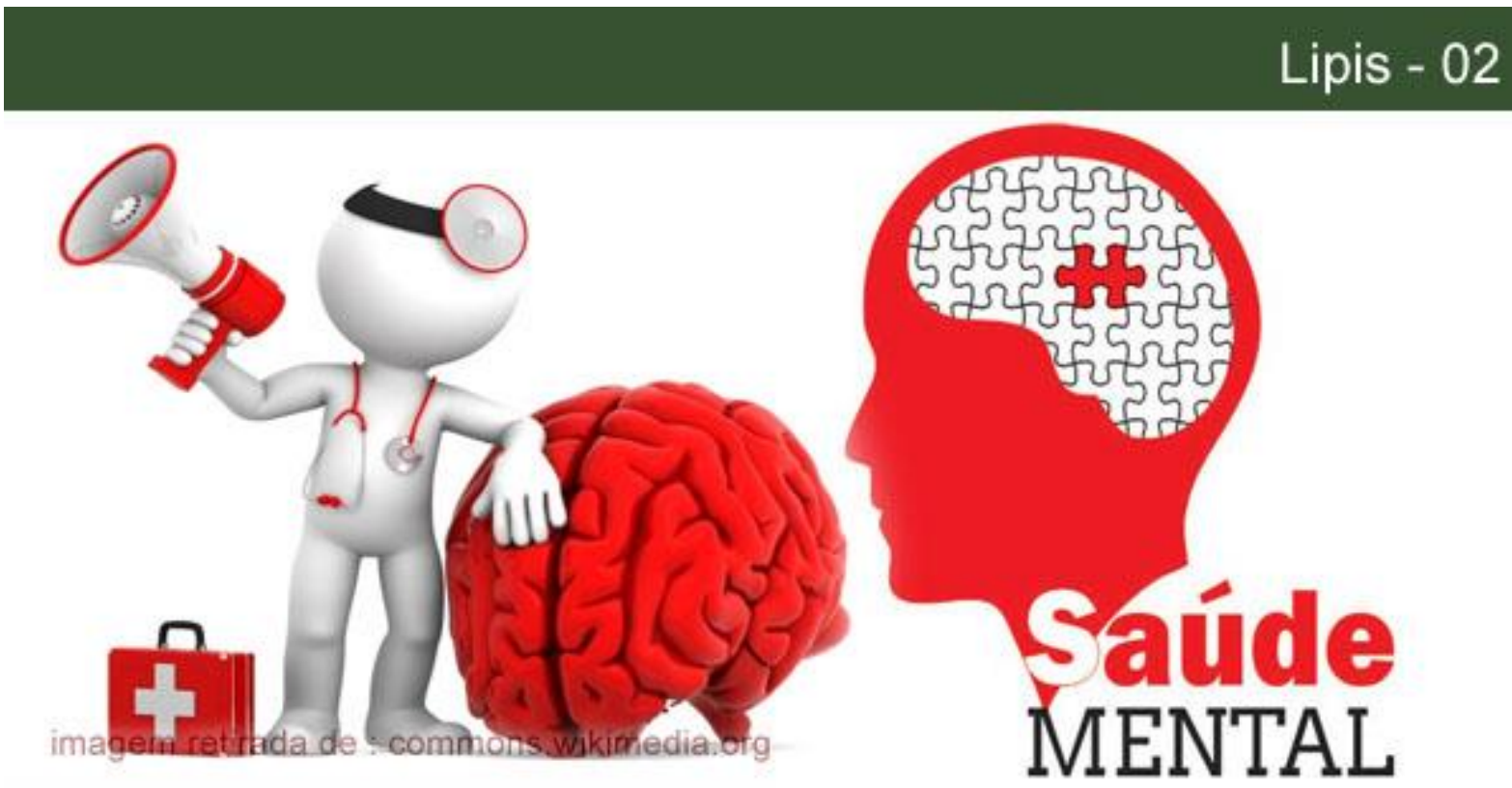

\title{
ENTRE O CUIDADO PSICOSSOCIAL E O PASSATEMPO: AS OFICINAS TERAPÊUTICAS NO CAMPO DA SAÚDE MENTAL
}

\author{
Ana Flavia Monteiro Lima \\ Psicóloga pela Universidade Federal de Uberlândia (UFU). E-mail: ana.flv.monteiro@gmail.com.
}

\section{Rodrigo Sanches Peres}

Psicólogo pela Universidade Estadual Paulista (Unesp). Professor do Programa de Pós-Graduação em Psicologia da Universidade Federal de Uberlândia (UFU). Especialista em Psicologia Clínica pelo Conselho Federal de Psicologia (CFP). Mestre e Doutor em Psicologia pela Universidade de São Paulo (USP), com Pósdoutorado pela Universidade de Lisboa (UL).E-mail: rodrigosanchesperes@yahoo.com.br.

Resumo: Nos serviços de saúde mental brasileiros, nomeadamente nos Centros de Atenção Psicossocial (CAPSs), diversas ferramentas de intervenção têm sido utilizadas. As oficinas terapêuticas se destacam como uma das principais. O presente estudo teve como objetivo, por meio do empreendimento de uma revisão da literatura, estabelecer um panorama da produção científica veiculada no formato de artigo sobre as oficinas terapêuticas no campo da saúde mental no país. Para tanto, foram consultadas as seguintes bases de dados: Periódicos Eletrônicos de Psicologia (PEPsic), Base de Dados de Enfermagem (BDEnf) e Scientific Electronic Library Online-Brasil (SciELO-Brasil). As referências localizadas foram triadas a fim de viabilizar o descarte de eventuais duplicidades e então selecionadas em função do tema. O corpus de análise foi constituído por 11 referências. Observou-se que os objetivos de tais referências foram relativamente diversificados, mas a maioria delas não apresentava informações sobre o enquadre das oficinas terapêuticas que abordaram. De qualquer forma, as referências apontaram que tais ferramentas de intervenção, em especial a partir da expressão artística e do trabalho, fomentavam a interação entre os usuários, bem como o desenvolvimento de diferentes habilidades e, como consequência, forneciam subsídios para o cuidado psicossocial. Em contrapartida, em algumas referências foram veiculados indícios de que as oficinas terapêuticas pesquisadas, ao menos em parte, se afiguravam como meras "tarefas" a serem cumpridas mecanicamente pelos usuários, pois foram concebidas ou acabaram funcionando como uma espécie de passatempo. O presente estudo, assim, pode ser considerado potencialmente útil para pesquisadores e profissionais de saúde interessados no assunto.

Palavras-chave: Saúde mental. Oficinas terapêuticas. Reforma Psiquiátrica.

\section{POLÊM!CA $\mid$ LABORE (}

Polêmica - Revista Eletrônica da Uerj - Rua São Francisco Xavier, 524, $1^{\circ}$ andar bloco D, sl.1001 • Tels.: +55 21 2334-4088 / 4087 • http://www.e-publicacoes.uerj.br/index.php/polemica/index http://www.labore.uerj.br • laboreuerj@yahoo.com.br 


\title{
BETWEEN PSYCHOSOCIAL CARE AND HOBBY: THERAPEUTIC WORKSHOPS IN MENTAL HEALTH FIELD
}

\begin{abstract}
In Brazilian mental health services, namely in the Psychosocial Care Centers (CAPSs), several intervention tools have been used. The therapeutic workshops stand out as one of the main ones. The present study aimed to establish, through a literature review, an overview of the scientific production carried out in the format of article about the therapeutic workshops in the mental health field in Brazil. The following databases were consulted: Periódicos Eletrônicos de Psicologia (PEPsic), Base de Dados de Enfermagem (BDEnf) and Scientific Electronic Library Online-Brasil (SciELO-Brasil). The localized references were sorted to enable the discarding of possible duplications and then selected according to the theme. The corpus of analysis consisted of 11 references. It was found that the objectives of such references were relatively diverse, but most of them did not provide information on the frame of the therapeutic workshops they addressed. In any case, the references pointed out that such intervention tools, specially from the artistic expression and the work, fomented the interaction between the users, as well as the development of different abilities and, consequently, they provided subsidies for the psychosocial care. On the other hand, in some references, there were indications that the therapeutic workshops researched, at least in part, appeared as mere tasks to be performed mechanically by the users, because were conceived or ended up functioning as a kind of hobby. The present study, therefore, can be considered potentially useful for researchers and health professionals interested in the subject.
\end{abstract}

Keywords: Mental health. Therapeutic workshops. Psychiatric Reform.

\section{Introdução}

No final da década de 1970, começaram a se intensificar no país as críticas aos tratamentos que, sob a égide do modelo hospitalocêntrico, eram impostos aos pacientes psiquiátricos e, com isso, a Reforma Psiquiátrica Brasileira passou a ganhar corpo. Alguns fatos, como a deflagração do Movimento dos Trabalhadores em Saúde Mental (MTSM), no contexto nacional, e o êxito da Psiquiatria Democrática, na Itália, foram marcantes para este processo e contribuíram para a implementação, em algumas cidades do país, de iniciativas voltadas à reorganização da assistência em saúde mental na perspectiva do cuidado psicossocial. Destaca-se neste sentido a criação do primeiro Centro de Atenção Psicossocial (CAPS) em 1987, na cidade de São Paulo, e também a instalação do primeiro Núcleo de Atenção Psicossocial (NAPS), em Santos. Porém, foi apenas em 2001, com a aprovação de um projeto de lei do deputado Paulo Delgado, que a centralidade dos manicômios foi confrontada mais incisivamente no âmbito das políticas públicas (BRASIL, 2005).

A Lei ${ }^{\circ}$ 10.216, de 6 de abril de 2001, estabeleceu originalmente os direitos das pessoas com transtornos mentais, de forma a superar a lógica da segregação e da exclusão. Tal documento regulamentou novas práticas em saúde mental no país, tendo definido que serviços comunitários e abertos deveriam ser privilegiados a fim de proporcionar um tratamento no sistema de saúde, pelos meios menos invasivos, visando à reintegração de tal população na família, no trabalho e na comunidade. Além disso, vedou a internação psiquiátrica em instituições com características asilares e a limitou a situações específicas, demarcadas pela

\section{POLÊM!CA $\mid$ LABORE}

Polêmica - Revista Eletrônica da Uerj - Rua São Francisco Xavier, 524, $1^{\circ}$ andar

bloco D, sl.1001 • Tels.: +55 21 2334-4088/4087 • http://www.e-publicacoes.uerj.br/index.php/polemica/index

http://www.labore.uerj.br • laboreuerj@yahoo.com.br 
insuficiência dos recursos extra-hospitalares diante das necessidades do caso (BRASIL, 2001). Acompanhando a Lei $n^{\circ} 10.216$, a Portaria $n^{\circ} 336$, de 19 de fevereiro de 2002, veio a regulamentar os CAPSs e os serviços de saúde equivalentes.

A partir de então, os CAPSs devem constituir "lugar de referência e tratamento para pessoas que sofrem com transtornos mentais, [...], cuja severidade e/ou persistência justifiquem sua permanência num dispositivo de cuidado intensivo, comunitário, personalizado e promotor de vida" (BRASIL, 2004, p. 13). Logo, os objetivos dos CAPSs são oferecer acompanhamento clínico e fomentar a "reinserção social dos usuários pelo acesso ao trabalho, lazer, exercício dos direitos civis e fortalecimento dos laços familiares e comunitários” (BRASIL, 2004, p. 13). E vale destacar que a Portaria $\mathrm{n}^{\circ} 336$ ainda distinguiu os seguintes tipos de CAPSs: CAPS I (com funcionamento em dois turnos), CAPS II (com funcionamento em dois ou três turnos), CAPS III (com funcionamento 24 horas por dia), CAPSi (voltado a crianças e adolescentes) e CAPSad (voltado a usuários de álcool e outras drogas) (BRASIL, 2002).

Nos CAPSs, bem como nos demais serviços comunitários de saúde mental, diversas ferramentas de intervenção são oferecidas para viabilizar o cuidado psicossocial. As oficinas terapêuticas se destacam como uma das principais, sendo que, de acordo com o Ministério da Saúde, podem ser compreendidas, em linhas gerais, como:

\footnotetext{
Atividades realizadas em grupo com a presença e orientação de um ou mais profissionais, monitores e/ou estagiários, [...] definidas através do interesse dos usuários, das possibilidades dos técnicos do serviço, das necessidades, tendo em vista a maior integração social e familiar, a manifestação de sentimentos e problemas, o desenvolvimento de habilidades corporais, a realização de atividades produtivas, o exercício coletivo da cidadania (BRASIL, 2004, p. 20).
}

Ainda acompanhando as diretrizes do Ministério da Saúde, as oficinas terapêuticas podem assumir três formatos primordiais: expressivas, de geração de renda e de alfabetização. As primeiras se caracterizam como um espaço no qual variadas linguagens são adotadas para favorecer, basicamente, a expressão plástica, corporal, verbal e/ou musical. Dentre tais linguagens destacam-se a pintura, o desenho, a dança, o teatro, a poesia e o canto, por exemplo. Já as segundas visam à criação de produtos por meio de atividades como a culinária, a marcenaria e a cerâmica, para comercialização e obtenção de retorno financeiro. As terceiras, por fim, incentivam o exercício da leitura e da escrita e são destinadas especificamente aos usuários que não foram adequadamente letrados.

\section{POLÊM!CA $\mid$ LABORE}


Tendo em vista a importância das oficinas terapêuticas para a consecução das metas da Reforma Psiquiátrica Brasileira, algumas pesquisas têm sido consagradas ao assunto. $\mathrm{O}$ presente estudo, assim, teve como objetivo, por meio do empreendimento de uma revisão da literatura, estabelecer um panorama da produção científica veiculada no formato de artigo sobre as oficinas terapêuticas no campo da saúde mental no país. Tal objetivo se justifica considerando-se que um mapeamento do conhecimento atualmente disponível a respeito da temática pode proporcionar informações úteis tanto para a prática clínica de diferentes profissionais de saúde quanto para o desenvolvimento de pesquisas futuras e, assim, auxiliar na consolidação da reorganização da assistência em saúde mental.

\section{Método}

Para subsidiar o levantamento bibliográfico referente ao presente estudo, foram consultadas as seguintes bases de dados: Periódicos Eletrônicos de Psicologia (PEPsic), Base de Dados de Enfermagem (BDEnf) e Scientific Electronic Library Online-Brasil (SciELOBrasil). A primeira e a segunda, como seus nomes já evidenciam, são especializadas em Psicologia e Enfermagem, respectivamente. Já a terceira possui escopo multidisciplinar. A opção por tais bases se justifica considerando-se que, no campo da saúde mental, as oficinas terapêuticas podem ser coordenadas por diferentes profissionais de saúde, ainda que tradicionalmente se observe certa predominância de psicólogos(as) e enfermeiros(as) nesta função.

Nas consultas realizadas junto às três bases de dados optou-se pelo cruzamento dos mesmos descritores, a saber: "oficinas" e "terapêuticas". Ocorre que tal estratégia se revelou mais produtiva do que outras possíveis em buscas prévias. Além disso, o campo selecionado para as buscas também não sofreu variação, tendo sido "resumo" nas três bases. E ressalte-se que as consultas foram concluídas no dia 21 de fevereiro de 2017 e não envolveram a utilização de quaisquer limites oferecidos pelas bases de dados, para que se pudesse obter um levantamento bibliográfico abrangente.

As referências localizadas foram inicialmente triadas a partir de seus títulos e resumos, visando ao descarte de eventuais duplicidades. A seguir, as referências triadas foram selecionadas com a utilização de um critério de inclusão básico: apresentar como tema principal as oficinas terapêuticas no campo da saúde mental conforme definidas pelo Ministério da

\section{POLÊM!CA $\mid$ LABORE}

Polêmica - Revista Eletrônica da Uerj - Rua São Francisco Xavier, 524, $1^{\circ}$ andar

bloco D, sl.1001 • Tels.: +55 21 2334-4088 / 4087 • http://www.e-publicacoes.uerj.br/index.php/polemica/index

http://www.labore.uerj.br • laboreuerj@yahoo.com.br 
Saúde. Inicialmente, recorreu-se à leitura dos resumos para tanto. Porém, em alguns casos a leitura dos textos completos foi necessária para a aplicação do critério de inclusão, pois os resumos não se mostraram suficientemente informativos. As referências selecionadas constituíram o corpus de análise e foram submetidas a uma leitura exaustiva, sempre pautada nos textos completos, para a devida apreciação.

\section{Resultados e discussão}

Na SciELO-Brasil, a busca resultou na localização de 13 referências. Destas, inicialmente sete foram selecionadas e seis foram excluídas. Já a consulta à PEPsic subsidiou a localização de nove referências. Descartando-se as duplicidades em relação à SciELO-Brasil, restaram oito referências, das quais inicialmente seis foram selecionadas e duas foram excluídas. Por fim, mediante a consulta à BDEnf, foram localizadas 12 referências. Descartando-se as duplicidades em relação à SciELO-Brasil e à PEPsic, restaram oito referências. E, destas, inicialmente quatro foram selecionadas e quatro foram excluídas.

Portanto, após a triagem realizada a fim de viabilizar o descarte de eventuais duplicidades e a execução da primeira fase de seleção das referências, amparada na leitura dos resumos, foram obtidas, no total, 17 referências. Contudo, como consequência da fase complementar de seleção, norteada pela leitura dos textos completos, seis referências foram excluídas por não atenderam ao critério de inclusão. Desse modo, o corpus de análise foi constituído por 11 referências. Em ordem cronológica crescente, são elas: Mendonça (2005), Cedraz e Dimenstein (2005), Ribeiro, Sala e Oliveira (2008), Dominguez e Paravidini (2009), Silva e Alencar (2009), Monteiro e Loyola (2009), Martins, Oliveira, Silva, Moreira e Souza (2010), Azevedo e Miranda (2011), Souza e Pinheiro (2012), Farias, Thofehrn, Andrade, Carvalho, Fernandes e Porto (2016) e Noronha, Folle, Guimarães, Brum, Schneider e Motta (2016).

Antes de iniciar a apreciação das referências selecionadas, é interessante sublinhar que parte das referências excluídas dizia respeito a ações que não poderiam ser adequadamente enquadradas como oficinas terapêuticas, quer sejam expressivas, de geração de renda ou de alfabetização. Ocorre que tais ações aparentemente possuíam um enfoque exclusivamente educativo. Uma referência excluída, por exemplo, descreveu grupos voltados à promoção da saúde do homem por meio de exposições dialogadas sobre doenças sexualmente transmissíveis

\section{POLÊM!CA $\mid$ LABORE}


ou problemas decorrentes do abuso de álcool e outras drogas. Outra referência excluída teve como foco uma intervenção cujo intuito era o desenvolvimento do autocuidado e a prevenção de dores na coluna. Logo, conclui-se que a expressão "oficina terapêutica", ou simplesmente "oficina", eventualmente é utilizada no âmbito da pesquisa de modo pouco criterioso, talvez acompanhando o que muitas vezes se observa no cotidiano da assistência em saúde.

Este problema também pode ser apontado como um dos fatores associados à inexistência de um maior número de pesquisas consagradas às oficinas terapêuticas no campo da saúde mental, fenômeno do qual, inclusive, é correlativa a seleção de uma quantidade reduzida de referências para a constituição do corpus do presente estudo. Cabe sublinhar que, em uma obra publicada há mais de 10 anos, Galletti (2004) já advertia que o volume de estudos sobre o tema não correspondia à crescente utilização das oficinas terapêuticas em serviços de saúde mental. Embora tais ferramentas de intervenção venham sendo cada vez mais empregadas, não necessariamente têm sido as mais pesquisadas no país. E algumas considerações da referida autora auxiliam na compreensão deste cenário.

Em primeiro lugar, porque Galletti (2004) observou que as oficinas terapêuticas são heterogêneas por definição, pois podem ser desenvolvidas a partir do recurso a variadas linguagens. Justamente por isso, não estão atreladas a uma teoria em específico. Em segundo lugar, porque diversas categorias profissionais podem trabalhar com estas práticas, o que tende a influenciar a delimitação daquilo que as caracterizaria em sua essência. Ou seja, as dificuldades quanto à operacionalização de um enquadramento mais preciso de tais ferramentas de intervenção poderiam constituir um obstáculo à realização de pesquisas a respeito. Em contrapartida, ainda acompanhando a autora, o fato de as oficinas terapêticas se situarem em um campo híbrido, aberto a intersecções de vários saberes, possibilitaria experiências mais ricas.

Posto isso, faz-se necessário mencionar que os objetivos das referências selecionadas se revelaram relativamente diversificados, o que pode ser considerado positivo, pois o assunto obviamente não se encontra esgotado. E, para ilustrar tal diversidade, cabe esclarecer quais foram estes objetivos, o que será feito a seguir agregando as referências selecionadas segundo a situação de coleta de dados. Inicialmente, serão contempladas as referências que veicularam dados coletados em campo especificamente para fins de pesquisa e que, assim, podem ser qualificadas como derivadas de pesquisas empíricas.

\section{POLÊM!CA $\mid$ LABORE}


Cedraz e Dimenstein (2005) buscaram compreender o funcionamento das oficinas terapêuticas em um CAPS. Com um propósito similar, Ribeiro, Sala e Oliveira (2008) se ocuparam da análise do alinhamento destas ferramentas de intervenção ao modo de atenção psicossocial. Já Dominguez e Paravidini (2009) investigaram o "fazer artístico" conforme usuários e profissionais de CAPSs. Monteiro e Loyola (2009) avaliaram, na perspectiva dos usuários, indicadores de qualidade das práticas em questão em um hospital-dia. Martins et al. (2010), também valorizando o ponto de vista dos usuários, exploraram o impacto das oficinas terapêuticas oferecidas em um CAPS. Em contraste, tanto Azevedo e Miranda (2011) quanto Noronha et al. (2016), com algumas especificidades, trabalharam com a percepção de familiares de usuários de CAPSs. Farias et al. (2016), por fim, se propuseram a conhecer a percepção de diversos profissionais de saúde (médicos, assistentes sociais, psicólogos e enfermeiros) acerca do funcionamento das oficinas terapêuticas em um CAPS.

Por outro lado, as referências de Mendonça (2005), Silva e Alencar (2009) e Souza e Pinheiro (2012) poderiam ser qualificadas como derivadas de relatos de experiência, pois visaram a descrever ações conduzidas a partir de demandas do cotidiano da assistência em saúde. A primeira reportou oficinas terapêuticas executadas em um hospital com usuários internados. Já a segunda discutiu o estatuto das produções de pacientes psicóticos oriundas destas ferramentas de intervenção conforme desenvolvidas em um centro de atenção diária. E a descrição de oficinas terapêuticas realizadas em um CAPSad por psicólogos foi o objetivo da terceira.

Porém, observou-se que apenas três referências - Souza e Pinheiro (2012), Cedraz e Dimenstein (2005) e Mendonça (2005) - forneceram informações sobre o enquadre das oficinas terapêuticas que abordaram, ou, mais especificamente, as tipificaram e informaram sua duração e frequência, os materiais utilizados, os responsáveis, os participantes e os critérios de inclusão. Tal achado pode ser considerado negativo, pois seria esperado que dados dessa natureza constassem de todas as referências, inclusive daquelas enquadradas como derivadas de pesquisas empíricas. Isso seria importante, inclusive, para que experiências bem-sucedidas pudessem ser reproduzidas em outros serviços de saúde mental ou para que se possibilitasse atingir uma melhor compreensão quanto aos desafios que se impõem à realização de oficinas terapêuticas.

\section{POLÊM!CA $\mid$ LABORE}


Na mais recente destas três referências, Souza e Pinheiro (2012) reportaram uma oficina terapêutica realizada em um CAPSad, quatro vezes por semana, com duração de duas horas, coordenada por dois psicólogos e uma estagiária de Letras. A partir daquilo que se pode depreender do texto, tratar-se-ia de uma oficina terapêutica expressiva. Ocorre que um poema - "Poema de sete faces", de Carlos Drummond de Andrade - foi selecionado como recurso mediador para, de acordo com os autores, proporcionar um "espaço de expressão, construção e transformação subjetiva" direcionado aos usuários em geral, por adesão espontânea, sem restrição quanto à participação, a não ser aquela determinada pelo número máximo de 15 participantes. Porém, o poema foi utilizado em um encontro em específico, o qual é explorado na referência, e outros recursos mediadores foram adotados nos demais encontros, mantendose o objetivo da oficina terapêutica.

Já a referência de autoria de Cedraz e Dimenstein (2005) apresentou uma caracterização de oficinas terapêuticas desenvolvidas em um CAPS. As autoras realizaram visitas sistemáticas a tal serviço de saúde e verificaram que as ferramentas de intervenção eram diversificadas quanto às linguagens - "culinária", "música", "coral”, "beleza” e "relaxamento", por exemplo - e eram oferecidas diariamente pelos profissionais do CAPS, sendo que duravam em média uma hora e meia e o critério de inclusão era a adesão espontânea.

Por fim, a referência de Mendonça (2005) relatou a experiência da própria autora com a realização de duas oficinas terapêuticas distintas, ambas oferecidas, por adesão espontânea, a usuários internados em um serviço de saúde hospitalar. Uma delas foi denominada "oficina de jornal" e, aparentemente, tratar-se-ia de uma prática expressiva. A outra oficina terapêutica, chamada pela autora de "oficina de salão de beleza", era dedicada ao cuidado da aparência das usuárias, pelo que, inicialmente, não se enquadraria adequadamente na tipologia estabelecida pelo Ministério da Saúde. A duração e a frequência não foram informadas em nenhum dos casos.

Portanto, as oficinas terapêuticas abordadas nas três referências que veicularam informações sobre enquadre, em linhas gerais, tinham duração de uma hora e meia a duas horas. A adesão espontânea era o único critério de inclusão dos participantes e havia diversificação quanto aos materiais utilizados e aos profissionais responsáveis pela coordenação, de forma que se pode deduzir que o mesmo se aplicaria às finalidades com que tais ferramentas de intervenção eram utilizadas, em que pese a aparente ênfase em oficinas terapêuticas expressivas. Porém,

\section{POLÊM!CA $\mid$ LABORE}

Polêmica - Revista Eletrônica da Uerj - Rua São Francisco Xavier, 524, $1^{\circ}$ andar

bloco D, sl.1001 • Tels.: +55 21 2334-4088 / 4087 • http://www.e-publicacoes.uerj.br/index.php/polemica/index http://www.labore.uerj.br • laboreuerj@yahoo.com.br 
apenas a referência de Souza e Pinheiro (2012) apresentou todos os dados esperados quanto ao enquadre. Ou seja, somente uma dentre as 11 referências que constituíram o corpus de análise poderia ser considerada suficientemente detalhada a este respeito.

Ainda há que se sintetizar os principais resultados reportados pelas referências selecionadas para os fins do presente estudo, o que será feito a seguir, retomando-se a ordem cronológica crescente. Mendonça (2005) defendeu que as oficinas terapêuticas realizadas em hospitais podem favorecer a reinvenção do cotidiano institucional mediante o incremento das trocas relacionais e o incentivo à expressão das singularidades. Já Cedraz e Dimenstein (2005) verificaram que, a despeito de seu potencial transformador, as práticas contempladas estavam funcionando como dispositivos de ocupação do tempo dos usuários no CAPS pesquisado. Observaram, igualmente, que as mesmas sempre partiam da iniciativa dos profissionais de saúde, e não dos usuários.

Ribeiro, Sala e Oliveira (2008) constataram que, nos CAPSs em que coletaram dados, algumas oficinas terapêuticas possibilitavam aos usuários o desenvolvimento de habilidades e promoviam a interação entre os mesmos. Outras, porém, eram desprovidas de significado para os usuários, visto que funcionavam como passatempo ou com o único propósito de produzir artesanato de "boa qualidade" para venda. Acompanhando estes achados, Domingues e Paravidini (2009) alertaram que o "fazer artístico" pode ensejar tanto a criação quanto a repetição, pois as oficinas terapêuticas pesquisadas, segundo os próprios usuários, se afiguravam, basicamente, como um locus de simbolização, elaboração, socialização e aprendizado, ou, em contraste, de ocupação, distração e mesmice. Dialogando com esta referência, Silva e Alencar (2009) propuseram que o que tornaria as práticas em questão de fato terapêuticas para pacientes psicóticos seria a possibilidade de, por meio delas, se estabelecer uma inserção estabilizadora no simbólico.

Os resultados veiculados por Monteiro e Loyola (2009) dão conta de que os indicadores de qualidade mais valorizados pelos participantes das oficinas terapêuticas pesquisadas foram aqueles relativos à estrutura (como local e materiais), ao manejo do coordenador (orientação, mediação das reuniões) e ao atendimento de suas necessidades (lugar prazeroso, melhoria da qualidade de vida e das relações sociais). E Martins et. al (2010) detectaram que os participantes de tais ferramentas de intervenção comumente referem que as mesmas promovem "bem-estar",

\section{POLÊM!CA $\mid$ LABORE}


“alegria", "relaxamento" e "sentimentos positivos", fazendo-o a partir do desenvolvimento de atividades produtivas ou criativas.

Azevedo e Miranda (2011) concluíram que familiares de usuários de CAPSs geralmente reconhecem que as oficinas terapêuticas contribuem para o tratamento de seus entes, mas identificam certas demandas reprimidas. Souza e Pinheiro (2012) relataram que a qualidade terapêutica da prática da qual se ocuparam se efetivou a partir das relações estabelecidas por meio da mesma. Sendo assim, advertiram que as oficinas terapêuticas não podem ser consideradas terapêuticas per se. Os profissionais de saúde entrevistados por Farias et al (2016), de forma semelhante, reconheceram a importância destas ferramentas de intervenção para a valorização dos aspectos saudáveis e das capacidades, bem como para a expressão da subjetividade dos usuários. Em que pese tal fato, apontaram, conforme os autores, a necessidade de se refletir permanentemente a respeito do papel das oficinas terapêuticas para que elas não se tornem apenas um espaço de entretenimento. Por fim, Noronha et al (2016) referiram que apenas metade dos familiares e/ou cuidadores de adolescentes vinculados a um CAPSi conhecia a função das práticas em questão. Ainda assim, parte deles mencionou que os adolescentes apresentaram mudanças comportamentais positivas depois de começarem a frequentá-las.

Em linhas gerais, portanto, a relevância das oficinas terapêuticas para a efetivação dos propósitos da Reforma Psiquiátrica Brasileira foi realçada pelas referências selecionadas, pois muitas delas apontaram que tais ferramentas de intervenção, nomeadamente a partir da expressão artística e do trabalho, fomentavam a interação entre os usuários, bem como o desenvolvimento de diferentes habilidades, sendo que, como consequência, ensejavam o cuidado psicossocial. Para tanto, todavia, caberia ao coordenador estimular o diálogo e respeitar as singularidades, de maneira a não incorrer em ações que remetem ao antigo modelo manicomial, como salientaram Mendonça (2005) e Silva e Alencar (2009), por exemplo. Porém, nas referências de Ribeiro et al (2008) e Cedraz e Dimenstein (2005) foram veiculados indícios de que as oficinas terapêuticas pesquisadas, ao menos em parte, se afiguravam como meras tarefas a serem cumpridas mecanicamente pelos usuários, pois foram concebidas ou acabaram funcionando como uma espécie de passatempo. E, como advertiram Domingues e Paravidini (2009), o que legitimaria uma oficina terapêutica como espaço de cidadania seria justamente a capacidade de trazer à tona o novo, o diferente.

\section{POLÊM!CA $\mid$ LABORE}


É interessante mencionar que algumas referências que não foram localizadas mediante o levantamento bibliográfico realizado para os fins do presente estudo corroboram os resultados reportados por certas referências selecionadas e contribuem para a elucidação de determinados aspectos dos mesmos. Santiago e Yasui (2011), por exemplo, realizando uma reconstrução histórica das relações existentes entre saúde mental e trabalho, advertiram que, na atualidade, eventualmente ainda se identificam resquícios de uma "lógica de ajuste" no desenvolvimento de oficinas terapêuticas. Afinal, tais ferramentas de intervenção - sobretudo, mas não apenas aquelas de geração de renda - muitas vezes são implementadas com o intuito exclusivo de controlar o tempo e a mente dos usuários à custa de diferentes modalidades de trabalho.

É precisamente assim que, como alerta Rauter (2000), as oficinas terapêuticas podem ensejar o exercício da "velha Psiquiatria". Seguindo a mesma linha de raciocínio, Andrade e Costa-Rosa (2014) relembram que, nas chamadas "colônias agrícolas", em que muitos pacientes psiquiátricos eram asilados no Brasil dos anos 1920, o trabalho era uma imposição no contexto do tratamento moral então hegemônico. Não obstante, Santiago e Yasui (2011) defendem que as oficinas terapêuticas, quando norteadas de fato pela perspectiva do cuidado psicossocial, viabilizam a operacionalização do trabalho como produtor de vida, auxiliando no resgate da cidadania e na construção da autonomia das pessoas com transtornos mentais. Em que pese a ênfase dos autores nas oficinas terapêuticas de geração de renda, é plausível propor que o mesmo possa se aplicar também àquelas expressivas e de alfabetização.

Mas como essa produção de vida seria efetivada? Obviamente tal pergunta não admite uma resposta unívoca. Todavia, cabe relembrar que as experiências de dois visionários da assistência em saúde mental no país tornaram patente, ainda na primeira metade do século XX, a necessidade de se privilegiar a iniciativa e valorizar as potencialidades dos usuários. Ocorre que tanto Osório César (1895-1979), no Hospital Psiquiátrico do Juquery, quanto Nise da Silveira (1905-1999), no Hospital Psiquiátrico Pedro II, demonstraram, cada qual a seu modo, que as variadas atividades nas quais pacientes psiquiátricos demonstram interesse por livre escolha fomentam a emergência de novas possibilidades existenciais para os mesmos ${ }^{1}$. Indubitavelmente trata-se de uma constatação que deve ser levada em conta por qualquer profissional de saúde que, na atualidade, coordena oficinas terapêuticas.

\footnotetext{
${ }^{1}$ Um detalhamento sobre o trabalho de Osório Cesar e Nise da Silveira pode ser encontrado em Andriolo (2003) e Frayze-Pereira (2003), respectivamente.
}

\section{POLÊM!CA $\mid$ LABORE}




\section{Considerações finais}

O presente estudo, como mencionado anteriormente, teve como objetivo estabelecer um panorama da produção científica veiculada no formato de artigo sobre as oficinas terapêuticas no campo da saúde mental no país. Ao fazê-lo, constatou-se, de início, que o número de referências consagradas ao tema é significativamente reduzido, levando-se em conta a importância de tais ferramentas de intervenção para a reorganização da assistência em saúde mental conforme proposta pela Reforma Psiquiátrica Brasileira. Além disso, observou-se que, em muitas referências, o termo "oficinas terapêuticas" foi empregado de uma maneira que pode ser considerada equivocada à luz das diretrizes estabelecidas pelo Ministério da Saúde, pois serviu para aludir a ações de caráter exclusivamente educativo.

Notou-se que, dentre as 11 referências que constituíram o corpus de análise, os objetivos foram relativamente diversificados, mas houve predominância de pesquisas empíricas em detrimento de relatos de experiência. E verificou-se que a maioria das referências selecionadas não apresentava informações sobre o enquadre das oficinas terapêuticas que abordaram. Talvez este seja o achado mais inesperado - e preocupante - do presente estudo, posto que a inexistência de certos dados dificulta a compreensão, por parte dos leitores, quanto ao funcionamento das práticas em questão, bem como um entendimento mais preciso de seus limites e suas possibilidades em diferentes contextos e junto a distintas populações.

$\mathrm{O}$ alcance do presente estudo é determinado, sobretudo, pelo foco em artigos. Por outro lado, tal foco foi definido reconhecendo-se a centralidade desta modalidade textual para a divulgação científica na atualidade, especialmente em se tratando de bases de dados de acesso gratuito a textos completos, como foi o caso. Portanto, é possível propor que o presente estudo proporciona um retrato, ao menos aproximado, do conhecimento atualmente disponível e mais difundido sobre as oficinas terapêuticas no campo da saúde mental, sendo, portanto, potencialmente útil para pesquisadores e profissionais de saúde interessados no assunto. Não obstante, novas revisões da literatura, voltadas à produção científica veiculada no formato de teses e dissertações, por exemplo, podem vir a complementar as informações aqui veiculadas.

\section{Referências}

ANDRADE, M. C.; COSTA-ROSA, A. O encontro da loucura com o trabalho: concepções e práticas no transcurso da história. Gerais: Revista Interinstitucional de Psicologia, Belo Horizonte, v. 7., n. 1, p. 27-41,

\section{POLÊM!CA $\mid$ LABORE}

Polêmica - Revista Eletrônica da Uerj - Rua São Francisco Xavier, 524, $1^{\circ}$ andar

bloco D, sl.1001 • Tels.: +55 21 2334-4088 / 4087 • http://www.e-publicacoes.uerj.br/index.php/polemica/index

http://www.labore.uerj.br • laboreuerj@yahoo.com.br 
jan. 2014. Disponível em: <http://www.fafich.ufmg.br/gerais/index.php/gerais/article/view/331/320>. Acesso em: 13 out. 2017.

ANDRIOLO, A. A “psicologia da arte” no olhar de Osório Cesar: leituras e escritos. Psicologia: Ciência e Profissão, Brasília, v. 23, n. 4, p. 74-81, dez. 2003. Disponível em:

<http://www.scielo.br/scielo.php?script=sci_arttext\&pid=S1414-98932003000400011\&lng=en\&nrm=iso>. Acesso em: 13 out. 2017.

AZEVEDO, D. M.; MIRANDA, F. A. N. Oficinas terapêuticas como instrumento de reabilitação psicossocial: percepção de familiares. Escola Anna Nery, Rio de Janeiro, v. 15, n. 2, p. 339-345, jun. 2011. Disponível em: <http://www.scielo.br/scielo.php?script=sci_arttext\&pid=S141481452011000200017\&lng=en\&nrm=iso>. Acesso em: 13 out. 2017.

BRASIL. Lei n 10.216 , de abril de 2001. Dispõe sobre a proteção e os direitos das pessoas portadoras de transtornos mentais e redireciona o modelo assistencial em saúde mental. Diário Oficial da União, Brasília, 9 abr. 2001. Disponível em: <http://www.planalto.gov.br/ccivil_03/leis/leis_2001/110216.htm>. Acesso em: 13 out. 2017.

Portaria no 336, de 19 de fevereiro de 2002. Dispõe sobre os Centros de Atenção Psicossocial - CAPS, para atendimento público em saúde mental, isto é, pacientes com transtornos mentais severos e persistentes em sua área territorial, em regime de tratamento intensivo, semi-intensivo e não intensivo. Diário Oficial da União, Brasília, 20 fev. 2002, Seção 1, p. 22. Disponível em: <http://bvsms.saude.gov.br/bvs/saudelegis/gm/2002/prt0336_19_02_2002.html>. Acesso em: 13 out. 2017.

Ministério da Saúde. Secretaria de Atenção à Saúde. Departamento de Ações Programáticas Estratégicas. Saúde mental no SUS: os Centros de Atenção Psicossocial. Brasília, 2004.

. Ministério da Saúde. Secretaria de Atenção à Saúde. Coordenação Geral de Saúde Mental. Reforma psiquiátrica e política de saúde mental no Brasil. Brasília, 2005.

CEDRAZ, A.; DIMENSTEIN, M. Oficinas terapêuticas no cenário da Reforma Psiquiátrica: modalidades desinstitucionalizantes ou não? Revista Mal-estar e Subjetividade, Fortaleza, v. 5, n. 2, p. 300-327, set. 2005. Disponível em:

<http://pepsic.bvsalud.org/scielo.php?script=sci_arttext\&pid=S151861482005000200006\&lng=pt\&tlng=pt.> . Acesso em: 13 out. 2017.

DOMINGUES, M. A.; PARAVIDINI, J. L. A construção de ofícios terapêuticos em saúde mental. Mental, Barbacena, v. 7, n. 13, dez. 2009. Disponível em:

<http://pepsic.bvsalud.org/scielo.php?script=sci_arttext\&pid=S167944272009000200004\&lng=pt\&tlng=pt . Acesso em: 13 out. 2017.

FARIAS, I. D.; THOFEHRN, M. B.; ANDRADE, A. P. M.; CARVALHO, L. A.; FERNANDES, H. N.; PORTO, A. R. Oficina terapêutica como expressão da subjetividade. Revista Eletrônica Saúde Mental, Álcool e Drogas, Ribeirão Preto, v. 12, n. 3, p. 147-153, set. 2016. Disponível em: <https://dx.doi.org/10.11606/issn.1806-6976.v12i3p147-153>. Acesso em: 13 out. 2017.

FRAYZE-PEREIRA, J. A. Nise da Silveira: imagens do inconsciente entre psicologia, arte e política. Estudos Avançados, São Paulo, v. 17, n. 49, p. 197-208, dez. 2003. Disponível em: <http://www.scielo.br/scielo.php?script=sci_arttext\&pid=S0103-40142003000300012\&lng=en\&nrm=iso>. Acesso em: 13 out. 2017.

GALLETTI, M. C. Oficina em saúde mental: instrumento terapêutico ou intercessor clínico? Goiânia: Editora UCG, 2004.

MARTINS, Á. K. L., OLIVEIRA, J. D., SILVA, K. V. L. G., MOREIRA, D. G. A., SOUZA, Â. M. A. Oficinas terapêuticas sob o olhar de usuários do CAPS: um estudo descritivo. Revista de Enfermagem UFPE OnLine,

\section{POLÊM!CA $\mid$ LABORE}

Polêmica - Revista Eletrônica da Uerj - Rua São Francisco Xavier, 524, $1^{\circ}$ andar

bloco D, sl.1001 • Tels.: +55 21 2334-4088 / 4087 • http://www.e-publicacoes.uerj.br/index.php/polemica/index

http://www.labore.uerj.br • laboreuerj@yahoo.com.br 
Recife, v. 4, n. 1, p. 75-81, jan. 2010. Disponível em:

<https://www.ufpe.br/revistaenfermagem/index.php/revista/article/viewFile/515/443>. Acesso em: 13 out. 2017.

MENDONÇA, T. C. P. As oficinas na saúde mental: relato de uma experiência na internação. Psicologia:

Ciência e Profissão, Brasília, v. 25, n. 4, p. 626-635, dez. 2005. Disponível em:

<https://dx.doi.org/10.1590/S1414-98932005000400011>. Acesso em: 13 out. 2017.

MONTEIRO, R. L.; LOYOLA, C. M. D. Qualidade de oficinas terapêuticas segundo pacientes. Texto \&

Contexto - Enfermagem, Florianópolis, v. 18, n. 3, p. 436-442, jul. 2009. Disponível em:

<https://dx.doi.org/10.1590/S0104-07072009000300005>. Acesso em: 13 out. 2017.

NORONHA, A. A.; FOLLE, D.; GUIMARÃES, A. N.; BRUM, M. L. B.; SCHNEIDER, J. F.; MOTTA, M. G. C. Percepções de familiares de adolescentes sobre oficinas terapêuticas em um centro de atenção psicossocial infantil. Revista Gaúcha de Enfermagem, Porto Alegre, v. 37, n. 4, dez. 2016. Disponível em: <https://dx.doi.org/10.1590/1983-1447.2016.04.56061>. Acesso em: 13 out. 2017.

RAUTER, C. Oficinas para quê? Uma proposta ético-estético-política para oficinas terapêuticas. In: AMARANTE, P. (Orgs). Ensaios: subjetividade, saúde mental, sociedade. Rio de Janeiro: Fiocruz, 2000. p. 267 277

RIBEIRO, L. A.; SALA, A. L. B.; OLIVEIRA, A. G. B. As oficinas terapêuticas nos centros de atenção psicossocial. Revista Mineira de Enfermagem, Belo Horizonte, v. 12, n. 4, p. 516-522, dez. 2008. Disponível em: < http://www.reme.org.br/artigo/detalhes/296>. Acesso em: 13 out. 2017.

SANTIAGO, E.; YASUI, S. O trabalho como dispositivo de atenção em saúde mental: trajetória histórica e reflexões sobre sua atual utilização. Revista de Psicologia da UNESP, v. 10, n. 1, p. 195-210, jan. 2011. Disponível em: <http://seer.assis.unesp.br/index.php/psicologia/article/view/582/538>. Acesso em: 13 out. 2017.

SILVA, T. J. F.; ALENCAR, M. L. O. A. Invenção e endereçamento na oficina terapêutica em um centro de atenção diária. Revista Latinoamericana de Psicopatologia Fundamental, São Paulo, v. 12, n. 3, p. 524-538, set. 2009. Disponível em: <https://dx.doi.org/10.1590/S1415-47142009000300008>. Acesso em: 13 out. 2017.

SOUZA, L. G. S.; PINHEIRO, L. B. Oficinas terapêuticas em um Centro de Atenção Psicossocial álcool e drogas. Aletheia, Canoas, n. 38-39, p. 218-227, dez. 2012. Disponível em: <http://pepsic.bvsalud.org/scielo.php?script=sci_arttext\&pid=S141303942012000200018\&lng=pt\&tlng=pt.>. Acesso em: 13 out. 2017.

Recebido em: 25/03/2018.

Aceito em: 04/06/2018.

\section{POLÊM!CA $\mid$ LABORE}

Polêmica - Revista Eletrônica da Uerj - Rua São Francisco Xavier, 524, $1^{\circ}$ andar bloco D, sl.1001 • Tels.: +55 21 2334-4088/4087 • http://www.e-publicacoes.uerj.br/index.php/polemica/index http://www.labore.uerj.br • laboreuerj@yahoo.com.br 